Journal of Pharmaceutical Science and Medical Reseaarch (PHARMED), 1 (2), 2018, 10-16

Available online at: http://e-journal.unipma.ac.id/index.php/pharmed

ISSN 2614-4840 (print) ISSN 2614-6118 (online)

\title{
Hubungan Kepatuhan Minum Obat Antihipertensi Terhadap Tercapainya Target Terapi Pasien Hipertensi di Puskesmas Wirobrajan Yogyakarta
}

\author{
Fani Mardina Cahyani \\ Prodi Farmasi, Fakultas Ilmu Kesehatan Dan Sains, Universitas PGRI, Madiun, Indonesia \\ fanimardina.farmasi@gmail.com
}

Received 08/14, 2018; Accepted 12/25, 2018

\begin{abstract}
Abstrak
Pusat Data dan Informasi Kesehatan (Pusdatin) Propinsi Daerah Istimewa Yogyakarta (DIY) 2016 berdasarkan Riskesdas 2013, propinsi DIY dengan prevalensi hipertensi 12,8\% menempati urutan ke 3 di Indonesia setelah Sulawesi Utara Dan Kalimantan Selatan. Data kasus kunjungan keluarga, penyakit hipertensi telah menjadi penyakit paling dominan kedua bagi kelompok keluarga di DIY. Sepuluh besar penyakit yang didiagnosa pada pasien rawat jalan di Puskesmas sesuai laporan sistem survailans terpadu, hipertensi menjadi urutan ke tiga setelah kasus diare dan influenzaTujuan penelitian ini adalah untuk mengetahui hubungan kepatuhan minum obat antihipertensi terhadap tercapainya target terapi pasien hipertensi di Puskesmas Wirobrajan Yogyakarta. Penelitian ini adalah jenis penelitian observasional dengan metode cross sectional. Metode pengambilan sampel dengan total populasi dengan kriteria inklusi yang melakukan kunjungan ke Puskesmas Wirobrajan. Sampel dalam penelitian ini sejumlah 50 pasien. Pengumpulan data primer dilakukan menggunakan kuesioner MMAS. Hasil uji chi-square antara tingkat kepatuhan dan tercapainya target terapi yaitu nilai p 0,005 $<0,05$ hal ini menunjukkan adanya hubungan antara tingkat kepatuhan dengan tercapainya target terapi.
\end{abstract}

Kata kunci:kepatuhan, hipertensi, target terapi

Center for Health Data and Information (Pusdatin) Province of Yogyakarta (DIY) 2016 based on Riskesdas 2013, DIY province with hypertension prevalence 12,8\% rank 3 in Indonesia after North Sulawesi and South Kalimantan. The case data of family visits, hypertension disease has become the second most dominant disease for family groups in DIY. The top ten diseases diagnosed in outpatients in Puskesmas according to the report of integrated surveillance system, hypertension became the third order after diarrhea and influenza case. The purpose of this study was to determine the relation of adherence to antihypertensive medication to the achievement of hypertension therapy target at Wirobrajan Health Center Yogyakarta. This research is a type of observational research with cross sectional method. Method of sampling with total population with inclusion criteria that visit to Wirobrajan Health Center. The sample in this study were 50 patients. Primary data collection was conducted using MMAS questionnaire. The result of chi-square test between adherence level and the achievement of therapeutic target that is $p$ value 0,005 $<0,05$ this indicates the relation between adherence level with the achievement of therapy target.

Keywords: adherence, hypertension, therapeutic target

\section{PENDAHULUAN}

Menurut World Health Organisation (WHO) 2011, Hipertensi mengakibatkan hampir 8 juta orang meninggal dunia setiap tahunnya. Hampir 1,5 juta adalah penduduk wilayah Asia Tenggara. Diperkirakan 1 dari 3 orang dewasa di Asia Tenggara menderita hipertensi. Statistik kesehatan dunia tahun 2012 melaporkan bahwa hipertensi adalah suatu kondisi berisiko tinggi yang menyebabkan sekitar 51\% dari kematian akibat stroke dan $45 \%$ dari penyakit jantung koroner. Kondisi ini menjadi tantangan dalam kesehatan masyarakat karena tingginya angka morbiditas dan mortalitas.

Pusat Data dan Informasi Kesehatan (Pusdatin) Propinsi Daerah Istimewa Yogyakarta (DIY) 2016 berdasarkan Riskesdas 2013, propinsi 
DIY dengan prevalensi hipertensi $12,8 \%$ menempati urutan ke 3 di Indonesia setelah Sulawesi Utara Dan Kalimantan Selatan. Data kasus kunjungan keluarga, penyakit hipertensi telah menjadi penyakit paling dominan kedua bagi kelompok keluarga di DIY.

Kepatuhan menjadi hal yang sangat penting bagi pasien hipertensi dalam mengontrol tekanan darah. Kepatuhan pasien mengkonsumsi obat merupakan hal sangat menunjang keberhasilan terapi, karena tanpa hal ini semua terapi pengobatan tidak akan mencapai hasil yang diinginkan. Ketidakpatuhan pada pasien hipertensi secara potensial dapat meningkatkan morbiditas, mortalitas dan biaya perawatan. Fakta menunjukkan penggunaan obat antihipertensif dapat mengurangi kejadian stroke $35 \%$ sampai $44 \%$ dan data penelitian lain menunjukkan bahwa penurunan tekanan darah hanya 2 $\mathrm{mmHg}$ pun sudah mengurangi $10 \%$ risiko kematian akibat stroke dan $7 \%$ kematian akibat serangan jantung (Fung dkk., 2007).

Puskesmas Wirobrajan merupakan fasilitas kesehatan tingkat pertama di wilayah Kecamatan Wirobrajan. Besarnya angka penyakit hipertensi di Puskesmas Wirobrajan tidak mengalami perubahan yang signifikan dari Januari 2015 - Juni 2016. Berdasarkan laporan bulanan SIMPUS Puskesmas Wirobrajan penyakit yang menduduki peringkat teratas adalah hipertensi dan diabetes melitus tipe 2. Sepuluh besar penyakit salah satunya adalah hipertensi merupakan prioritas penanganan yang harus segera diselesaikan untuk mencegah meledaknya prevalensi hipertensi (Profil Kesehatan, 2016).

\section{METODE}

Rancangan penelitian ini adalah penelitian observasional dengan desain potong lintang (cross sectional). Data kepatuhan dikumpulkan berdasarkan hasil pengisian kuesioner MMAS pada saat pasien kontrol ke Puskesmas Wirobrajan Yogyakarta.

\section{Alat dan Bahan}

Bahan dan sumber data yang digunakan dalam penelitian ini adalah data primer diperoleh dengan pengisian kuesioner oleh pasien. Data sekunder diperoleh dari riwayat penyakit dan nilai tekanan darah pasien, diambil dari catatan medis pasien. Pengumpulan data dilakukan dengan wawancara dan pengisian kuesioner pasien. antara lain:

Alat yang digunakan dalam penelitian ini

1. Catatan medik

Catatan medik berupa informasi yang tertulis mengenai riwayat kondisi pasien, tekanan darah awal, obat antihipertensi yang diperoleh.

2. Lembar informed consent

3. Lembar informasi karakteristik pasien

Data karakteristik pasien berupa nama, usia, jenis kelamin, pekerjaan, lama diagnosa penyakit, status merokok, berat badan, tinggi badan, riwayat penyakit keluarga.

4. Kuesioner MMAS.

Kuesioner MMAS yang digunakan dalam penelitian ini terdiri dari 8 butir pertanyaan. Kuesiner asli berbahasa inggris, dalam penelitian ini menggunakan MMAS yang sudah diterjemahkan oleh Ingrid Faustin tahun 2012 di di Fakultas llmu Budaya, Jurusan Bahasa Inggris, Universitas Gadjah Mada.

\section{Prosedur Kerja}

Penelitian dilakukan pada pasien dengan diagnosis hipertensi yang datang untuk kontrol di Puskesmas Wirobrajan Yogyakarta. Pemilihan subjek penelitian dilakukan secara consecutive sampling terhadap kelompok penderita hipertensi yang telah diberikan terapi. Data diperoleh berdasarkan rekam medik dan jawaban kuesioner pasien.

1. Memberikan penjelasan kepada pasien berkaitan dengan penelitian yang akan kita lakukan kemudian memberikan surat pernyataan berupa inform consent sebagai kesediaan pasien untuk menjadi subjek penelitian.

2. Wawancara langsung dilakukan untuk mendapatkan data karakteristik pasien dan mendampingi pasien mengisi kuesioner MMAS.

3. Melengkapi data primer yang diperoleh dari wawancara langsung dengan data pada rekam medik pasien hipertensi yang menjalani pengobatan rawat jalan di Puskesmas Wirobrajan Yogyakarta. 


\section{HASIL DAN PEMBAHASAN}

Penelitian ini bertujuan untuk mengetahui hubungan antara kepatuhan minum obat antihipertnsi terhadap tercapainya target terapi pasien hipertensi. Target terapi yang diaksud disini yaitu penurunan tekanan darah. Target tekanan darah yang direkomendasikan JNC 8 yaitu usia $\geq$ 60 tahun target penurunan tekanan darah sistolik < $150 \mathrm{mmHg}$ dan tekanan darah diastolik $<90$ $\mathrm{mmHg}$, rentang usia $\geq 18-60$ tahun dengan / tanpa penyakit ginjal kronik dan diabetes target penurunan tekanan darah sistolik $<140 \mathrm{mmHg}$ dan tekanan darah diastolik < $90 \mathrm{mmHg}$ (James dkk., 2014). Kepatuhan pasien dalam meminum obat antihipertensi dinilai dengan kusioner MMAS.

Penelitian ini dilakukan pada bulan Juli hingga September 2016 di Puskesmas Wirobrajan Yogyakarta. Penelitian ini adalah observasional dengan desain cross sectional dan diikuti oleh 50 pasien. Metode pengambilan sampel dilakukan dengan consecutive sampling, yaitu peneliti memilih subjek berdasarkan pertimbangan kriteria inklusi dan eksklusi penelitian, dan mampu memberikan informasi memadai untuk penelitian.

\section{Karakteristik Pasien}

Karakteristik pasien dalam penelitian ini meliputi jenis kelamin, usia, pendidikan, pekerjaan, IMT, penyakit penyerta, status merokok dan lama sakit hipertensi (Tabel 1). Sejumlah 50 pasien yang terlibat dalam penelitian ini diperoleh hasil bahwa jumlah penderita hipertensi baik lakilaki maupun perempuan adalah sama. Dari segi usia didapatkan hasil bahwa $84 \%$ pasien berusia $\geq$ 60 tahun. Tekanan darah akan semakin meningkat seiring dengan bertambahnya usia dan kelompok umur $\geq 75$ tahun berisiko 11,53 kali untuk menderita hipertensi. Hal ini dikarenakan efisiensi sistem kardiovaskular mengalami penurunan dan masalah-masalah yang berhubungan dengan fungsi sistem tersebut (Curb dkk., 1996).

Dari hasil perhitungan IMT diketahui bahwa $40 \%$ pasien memiliki berat badan normal (IMT 18,5-22,9) dan $26 \%$ pasien masuk dalam kategori obese I (IMT 25,0-29,9). Walaupun belum diketahui secara pasti hubungan hipertensi dengan obesitas, namun terbukti bahwa daya pompa jantung dan sirkulasi volume darah penderita obesitas dengan hipertensi lebih tinggi daripada penderita hipertensi dengan berat badan normal.

Obesitas juga berdampak pada kekuatan darah mendorong dinding arteri saat jantung memompa darah keluar semakin tinggi (Anggara dan Prayitno, 2013). Namun, dalam beberapa referensi menyebutkan tingginya tekanan darah disebabkan adanya timbunan lemak pada pembuluh darah. Pada orang dengan kelebihan berat badan, tekanan darahnya cenderung tinggi karena seluruh organ tubuh harus bekerja lebih kuat untuk memenuhi kebutuhan energi yang lebih besar termasuk organ jantung yang harus berkontraksi lebih kuat karena banyaknya timbunan lemak yang menyebabkan pembuluh darah mengalami penyempitan sehingga tekanan darah menjadi tinggi (Depkes R.I, 2007).

Subjek pasien hipertensi di Puskesmas Wirobrajan Yogyakarta, 29 orang mengalami hipertensi dengan berbagai penyakit penyerta, 20 orang diantaranya dengan penyakit penyerta DM. Hipertensi dan DM adalah kondisi umum yang terjadi di masyarakat dan merupakan faktor resiko penting terjadinya penyakit kardiovaskuler. Hipertensi lebih sering terjadi pada populasi diabetes dibandingkan populasi non-diabetes. Lebih dari $75 \%$ pasien diabetes mempunyai tekanan darah lebih dari 130/80 $\mathrm{mmHg}$ atau mengkonsumsi obat-obatan hipertensi (KDOQI, 2007). Hipertensi dapat terjadi bersamaan dengan diabetes. Patogenesis hipertensi pada diabetes merupakan proses yang komplek dan belum sepenuhnya dapat dijelaskan. Disfungsi otonom, aktivasi Renin Angiotension Aldosteron System $(R A A S)$, resistensi insulin, disfungsi endotel dan kekakuan dinding pembuluh darah arteri merupakan sebagian faktor yang diketahui berkontribusi pada terjadinya hipertensi pada diabetes (Sukmana dan Sumantri, 2014).

\section{Hubungan Kepatuhan Terhadap Tercapainya Target Terapi}

Kepatuhan pasien hipertensi di Puskesmas Wirobrajan Yogyakarta diukur dengan kuesioner MMAS. Skoring didapatkan dari jawaban pasien dalam kuesioner yang terdiri dari 8 item pertanyaan. Adapun hasil pengukuran kepatuhan pasien dapat dilihat pada Tabel 2. 
Journal of Pharmaceutical Science and Medical Reseaarch (PHARMED), 1 (2), 2018, 9-16

Available online at: http://e-journal.unipma.ac.id/index.php/pharmed

ISSN 2614-4840 (print) ISSN 2614-6118 (online)

Tabel 1. Karakteristik Pasien Puskesmas Wirobrajan Yogyakarta

\begin{tabular}{|c|c|c|c|}
\hline \multicolumn{2}{|c|}{ Karakteristik Responden } & \multirow{2}{*}{$\begin{array}{l}\mathbf{n} \\
25 \\
\end{array}$} & \multirow{2}{*}{$\begin{array}{l}\% \\
50 \\
\end{array}$} \\
\hline Jenis & Laki - laki & & \\
\hline Kelamin & Perempuan & 25 & 50 \\
\hline \multirow[t]{2}{*}{ Usia } & $<60$ tahun & 8 & 16 \\
\hline & $\geq 60$ tahun & 42 & 84 \\
\hline \multirow{3}{*}{ Pendidikan } & $<$ SMP & 8 & 16 \\
\hline & SMP - SMA & 34 & 68 \\
\hline & $>$ SMA & 8 & 16 \\
\hline \multirow[t]{3}{*}{ Pekerjaan } & Wiraswasta & 23 & 46 \\
\hline & Pensiun & 17 & 34 \\
\hline & IRT & 10 & 20 \\
\hline \multirow[t]{4}{*}{ IMT } & Kurang $(<18,5)$ & 5 & 10 \\
\hline & Normal $(18,5-22,9)$ & 20 & 40 \\
\hline & $\begin{array}{l}\text { Resiko obese ( } 23,0 \text { - } \\
24,9)\end{array}$ & 12 & 24 \\
\hline & Obese I $(25,0-29,9)$ & 13 & 26 \\
\hline \multirow{4}{*}{$\begin{array}{l}\text { Penyakit } \\
\text { Penyerta }\end{array}$} & HT saja & 16 & 32 \\
\hline & $\mathrm{HT}+\mathrm{DM}$ & 20 & 40 \\
\hline & HT + Gout & 4 & 8 \\
\hline & HT + lainnya* & 10 & 20 \\
\hline \multirow[t]{2}{*}{ Merokok } & $\mathrm{Ya}$ & 15 & 30 \\
\hline & Tidak & 35 & 70 \\
\hline \multirow{3}{*}{$\begin{array}{l}\text { Lama } \\
\text { Diagnosis }\end{array}$} & $<1$ tahun & 8 & 16 \\
\hline & $1-4$ tahun & 26 & 52 \\
\hline & $\geq 5$ tahun & 16 & 32 \\
\hline
\end{tabular}

Tabel 2. Distribusi Tingkat Kepatuhan Pasien Hipertensi Di Puskesmas Wirobrajan Yogyakarta Bulan Agustus 2016

\begin{tabular}{ccc}
\hline Tingkat Kepatuhan & n & \% \\
\hline Rendah & 19 & 38 \\
\hline Sedang & 20 & 40 \\
\hline Tinggi & 11 & 22 \\
\hline
\end{tabular}

Pengukuran kepatuhan dilakukan 1 kali saat penelitian yaitu pada bulan Agustus 2016. Hasil pengukuran tingkat kepatuhan pasien hipertensi di Puskesmas Wirobrajan Yogyakarta didapatkan 40 $\%$ pasien memiliki kepatuhan sedang. Kepatuhan mengacu pada tindakan pasien untuk mengkonsumsi obat sesuai aturan pakai yang diberikan (Osterberg and Blaschke, 2005). Dari hasil penelitian, butir ke 8 pada kuesioner MMAS dimungkinkan untuk dilakukan analisa secara deskriptif dimana hasilnya dapat menggambarkan berbagai keluhan pasien yang menyebabkan ketidakpatuhan (Tabel 3).
Tabel 3. Alasan Ketidakpatuhan Pasien Hipertensi Di Puskesmas Wirobrajan Yogyakarta

\begin{tabular}{lccc}
\hline \multicolumn{1}{c}{ Alasan ketidakpatuhan } & \multicolumn{2}{c}{ Jumlah } \\
\cline { 2 - 3 } & $\mathbf{n}$ & \% \\
\hline Lupa karena aktivitas & 5 & 12,82 \\
\hline $\begin{array}{l}\text { Sengaja tidak minum karena merasa } \\
\text { sembuh }\end{array}$ & 13 & 33,33 \\
\hline Tidak nyaman dengan efek samping obat & 8 & 20,51 \\
\hline Tidak tahu obat harus diminum rutin & 9 & 23,07 \\
\hline Tidak percaya dengan obat sintesis & 2 & 5,12 \\
\hline $\begin{array}{l}\text { Kesulitan mengingat aturan minum obat } \\
\text { sebelum makan }\end{array}$ & 2 & 5,12 \\
\hline
\end{tabular}

Dari hasil wawancara 13 pasien mengungkapkan sengaja tidak minum obat karena merasa sembuh, 9 pasien tidak mengetahui obat hipertensi harus diminum rutin, 8 pasien mengeluhkan mengenai efek samping obat hipertensi seperti batuk kering, sering buang air kecil, 5 pasien mengungkapkan lupa minum obat karena alasan aktivitas. Alasan yang dikemukakan oleh pasien menunjukkan kurangnya informasi 
Journal of Pharmaceutical Science and Medical Reseaarch (PHARMED), 1 (2), 2018, 9-16

Available online at: http://e-journal.unipma.ac.id/index.php/pharmed

ISSN 2614-4840 (print) ISSN 2614-6118 (online)

pasien mengenai penyakit hipertensi dan pengobatannya.

Ada 2 pasien mengeluhkan kesulitan mengingat aturan minum obat sebelum makan yaitu pasien yang mendapatkan obat captopril. Penggunaan captopril sebaiknya dalam keadaan perut kosong (Medscape, 2016). Kita sebagai tenaga kesehatan dapat mengkomunikasikan kepada pasien bahwa asumsi perut kosong adalah 1 jam sebelum makan atau 2 jam setelah makan.

Tabel 4 menunjukkan proporsi pasien hipertensi + DM dengan tingkat kepatuhan tinggi paling banyak yaitu $16 \%$. Kepatuhan yang tinggi tersebut karena pasien mendapatkan obat (obat DM danHT) dengan waktu minum hampir bersamaan. Hasil uji fisher nilai $\mathrm{p}=0,003<0,05$ hal ini menunjukkan ada hubungan antara penyakit penyerta dengan tingkat kepatuhan

Tabel 4. Tabel Tingkat Kepatuhan Kelompok Hipertensi Dengan atau Tanpa Penyakit Penyerta

\begin{tabular}{|c|c|c|c|c|c|c|c|}
\hline \multirow{3}{*}{$\begin{array}{l}\text { Diagnosa } \\
\text { Penyakit }\end{array}$} & \multicolumn{6}{|c|}{ Tingkat kepatuhan } & \multirow[t]{3}{*}{ Nilai p } \\
\hline & \multicolumn{2}{|c|}{ Rendah } & \multicolumn{2}{|c|}{ Sedang } & \multicolumn{2}{|c|}{ Tinggi } & \\
\hline & $\mathbf{n}$ & $\%$ & $\mathbf{N}$ & $\%$ & $\mathbf{n}$ & $\%$ & \\
\hline HT & 8 & 16 & 8 & 16 & 0 & 0 & \\
\hline HT + DM & 5 & 10 & 7 & 14 & 8 & 16 & $0,003 *$ \\
\hline HT+ Gout & 0 & 0 & 1 & 2 & 3 & 6 & \\
\hline HT $\quad+$ & 6 & 12 & 4 & 8 & 0 & 0 & \\
\hline Lainnya & & & & & & & \\
\hline
\end{tabular}

Penelitian yang dilakukan Lee, dkk (2006) menunjukkan bahwa pasien kronis termasuk hipertensi dengan DM 2 rata-rata kepatuhan minum obat meningkat kurang lebih $80 \%$ selama 8 bulan. Peningkatan kepatuhan minum obat ini menurunkan tekanan darah sistolik dan diastolik. Kesimpulan penelitian tersebut ada hubungan yang bermakna antara kepatuhan minum obat terhadap tercapainya tekanan darah (Lee dkk., 2006).

Menilai tingkat kepatuhan pasien penting dilakukan agar tercapai efektifitas dan efisiensi pengobatan, serta untuk memonitoring keberhasilan dari pengobatan (derajat kesehatan). Hasil pengukuran kepatuhan dapat digunakan oleh tenaga kesehatan untuk melakukan evaluasi, rekomendasi alternatif pengobatan, dan perubahan komunikasi untuk lebih meningkatkan kepatuhan pasien (Fajar, 2009).

Ketercapaian target terapi tidak akan optimal tanpa adanya kesadaran dari pasien sendiri akan pentingnya kedisiplinan mengkonsumsi obat jangka panjang, bahkan dapat menyebabkan kegagalan terapi, serta dapat pula menimbulkan komplikasi yang sangat merugikan (Hussar, 1995). Hasil uji chi-square antara tingkat kepatuhan dan tercapainya target terapi yaitu nilai p $0,005<0,05$ hal ini menunjukkan adanya hubungan antara tingkat kepatuhan dengan tercapainya target terapi.

Tabel 5. Tabel Hubungan Tingkat Kepatuhan Terhadap Tercapainya Target Terapi

\begin{tabular}{llllll}
\hline \multirow{2}{*}{$\begin{array}{l}\text { Tingkat } \\
\text { Kepatuhan }\end{array}$} & \multicolumn{2}{l}{ Tercapai } & \multicolumn{2}{c}{$\begin{array}{c}\text { Tidak } \\
\text { Tercapai }\end{array}$} & Nilai p \\
\cline { 2 - 5 } & $\mathbf{N}$ & $\mathbf{\%}$ & $\mathbf{n}$ & $\mathbf{\%}$ & \\
\hline Rendah & 6 & 31,57 & 13 & 68,42 & \multirow{0}{*}{$\mathbf{0 , 0 0 5 *}$} \\
\hline Sedang & 15 & 75,00 & 5 & 25,00 & \\
\hline Tinggi & 9 & 81,81 & 2 & 18,18 & \\
\hline Total & $\mathbf{3 0}$ & & $\mathbf{2 0}$ & & \\
\hline
\end{tabular}

*Analisis Chi-Square

Penelitian Ramadhan (2010) telah dilakukan uji korelasi untuk mngetahui adanya pengaruh kepatuhan terhadap hasil terapi. Dalam hal ini yang dikorelasikan adalah kategori MMAS dengan tekanan darah. Setelah dianalisi dengan uji chi-square angka signifikansi $0,002<0,05$ didapatkan adanya peredaan yang signifikan antara kepatuhan dengan hasil penurunan tekanan darah sehingga dapat disimpulkan bahwa kepatuhan tinggi dapat menurunkan tekanan darah (Ramadhan, 2010).

\section{KESIMPULAN}

Dari penelitian yang telah dilakukan, ada hubungan antara kepatuhan pasien dalam minum obat antihipertensi terhadap tercapainya target terapi pasien hipertensi. Pasien yang mempunyai tingkat kepatuhan tinggi adalah pasien dengan penyakit penyerta DM. Adanya penyakit penyerta berpengaruh secara langsung terhadap kompleksitas pengobatan, banyaknya jumlah obat, besarnya biaya pengobatan dan berpengaruh terhadap motivasi untuk berobat.

\section{DAFTAR PUSTAKA}

Azwar, S., 2003. Reabilitas Dan Validitas. Pustaka Pelajar, Yogyakarta.

Barry, L.C. 2004, Implementing the New Guidelines for Hypertension : JNC VII, ADA, WHA - ISH, $J$ Management Care Pharm., 10 (5) : 18-25. 
Journal of Pharmaceutical Science and Medical Reseaarch (PHARMED), 1 (2), 2018, 9-16

Available online at: http://e-journal.unipma.ac.id/index.php/pharmed

ISSN 2614-4840 (print) ISSN 2614-6118 (online)

Cahyani, M. F., 2016, 'Hubungan Kepatuhan Dan

Kesesuaian Terapi Dengan Guideline

Terhadap Tercapanya Target Terapi Pasien

Hipertensi Di Puskesmas Wirobrajan

Yogyakarta'. Tesis. Universitas Gadjah

Mada, Yogyakarta.

Chang, C. dan Green, S., 2011. Hypertension Management in the Dominican Republic: Factors Affecting Medication

Adherence. Health Horizons

International Summer Interns, 2 : 8-12.

Depkes, 2006. Pharmaceutical Care Untuk Penyakit Hipertensi. Departemen

Kesehatan RI, Jakarta.

Depkes, 2007. Pharmaceutical Care Untuk Penyakit Hipertensi. Departemen Kesehatan RI, Jakarta.

Depkes, L., 2013. Riset Kesehatan Dasar 2013. Departemen Kesehatan RI, Jakarta.

DiPiro, J., Talbert, R., Yee, G., Matzke, G., Wells, B., dan Posey, L.M., 2008. Pharmacotherapy: A Pathophysiologic Approach, 7 edition. ed.McGraw-Hill Medical, New York.

Faustine, I., 2012. 'Evaluasi Pengaruh Konseling Farmasis Terhadap Hasil Terapi Pasien Hipertensi Usia Lanjut di Poliklinik Jantung RSUD UNDATA Palu Periode November-Desember 2011'.Thesis. Universitas Gadjah Mada, Yogyakarta.

Faujiah, R. dan Lefi, A., 2014. Peran Angiotensin Converting Enzym Inhibitor (ACEI) pada Hipertensi,dalam: Hipertensi Manajemen Komprehensif. Pusat Penerbitan dan Percetakan Unair (AUP), Surabaya, hal. 203-217.
Fitriani. 2011. Evaluasi Penggunaan Terapi Antihipertensi Terhadap Tekanan Darah Pradialisis Pada Pasien Rawat Jalan Dengan End Stage Renal Disease (ESRD) Yang Menjalani Hemodialisis Rutin Di RS PKU Muhammadiyah Yogyakarta. Jurnal Manajemen dan Pelayanan Farmasi Vol. 1 No. 3 / September 2011.

Fung, V., Huang, J., Brand, R., Newhouse, J.P., dan Hsu, J., 2007. Hypertension treatment in a medicare population : adherence and systolic blood pressure control. Clinical Theurapeutics, 29 : 972-984

KDOQI, 2007. KDOQI Clinical Practice Guidelines and Clinical Practice Recommendations for Diabetes and Chronic Kidney Disease 42: S12-54.

Lee, J.K., Grace, K.A., dan Taylor, A.J., 2006. Effect of Pharmacy Care Program on Medication Adherence and Persistence, Blood Pressure, and Low-Density Lipoprotein Cholesterol : a randomized controlled trial. JAMA, 296 : 25632571.

James PA, Oparil S, Carter BL, dan et al, 2014. 2014 evidence-based guideline for members appointed to the eighth joint national committee (jnc 8). JAMA, 311: 507-520.

Johnson, M., 2004. Prevalence of Comorbid Hypertension and Dyslipidemia and Associated Cardiovascular Disease. Am. J. Manage Care, 10: 926-932.

Kaplan, N. dan Weber, M.A., 2010. Hypertension Essentials 2010. Jones \& Bartlett Learning, Brooklyn, New York.

Matfin, G. dan Porth, C.M., 2011. Disorder of Blood Flow and Blood Pressure, dalam: Essensials of Pathophysiology. Lippincott Williams \& Wilkins, hal. 422-438. 
Journal of Pharmaceutical Science and Medical Reseaarch (PHARMED), 1 (2), 2018, 9-16

Available online at: http://e-journal.unipma.ac.id/index.php/pharmed

ISSN 2614-4840 (print) ISSN 2614-6118 (online)

Morisky, D., Krousel-Wood, M., dan Ward, H., 2008. Predictive Validity if A Medication Adherence Measure in an Outpatient Setting. $J$ Health-Syst. Pharm, 10: 48-54.

OBRA, 1990. Omnibus Budget Reconciliation.Act of 1990. Pub. L. No. 101 - 508 and 4401, 104 stat 1388 ,

Osterberg, LMD, and Blaschke, TMD, 2005, adherence to Medication, New England Journal Medicine, 353 : 487- 497.

Palaian, S., Prabhu, M., dan Shankar, P.R., 2006. Patient Counseling by Pharmacist - A Focus on Chronic Illness. Pak. J. Pharm. Sci., 19 (1): 6265.

Ramadhan, M.A., 2012. 'Pengaruh Ketepatan Terapi dan Kepatuhan Terhadap Hasil terapi Hipertensi di Poliklinik Penyakit Dalam RSUP DR. Sardjito Yogyakarta Periode Februari-April 2012'. Thesis. Universitas Gadjah Mada Yogyakarta.

Saseen, J.J., 2013. Essensial Hypertension, dalam: Applied Therapeutics: The Clinical Use of Drugs, Tenth Editon. Lippincott Williams \& Wilkins, New York, 14 : 291-329.

Saseen, J.J. dan Carter, B.L., 2008. Hypertension, dalam: Pharmacotherapy- A Pathophysiologic Approach 8th Edition. McGraw-Hill, New York, hal. 139-169.

WHO, 2003. Adherence to Long Term Therapy : Evidence for Action. Switzerland.

WHO, 2011. The Global Burden of Disease : 2007 update. Geneva : WHO Library Cataloguing in-Publication Data, 4051.

WHO, 2011. Noncomunicable Disease in The South East Asia Region: Situation and Response 2011. World Health Organization, India.
Williams, G.H., 2000. Penyakit Vaskuler Hipertensif, dalam: Isselbacher, K.J., Braunwald, E., Wilson, J.D., Martin, J.B., Fauci, A.S., Kasper, D.L., dkk. (Eds.), Harrison: Prinsip-Prinsip Ilmu Penyakit Dalam. Penerbit Buku Kedokteran EGC, Jakarta, hal. 12561272 . 
